\title{
Comunicación
}

\section{EVIDENCIA SEROLÓGICA DE ANTICUERPOS CONTRA EL VIRUS DE LA RETICULOENDOTELIOSIS EN GALLINAS REPRODUCTORAS DE LIMA}

\author{
Elia Salas C. ${ }^{1}$, Eliana Icochea D. ${ }^{2}$, Rosa González V. ${ }^{2}$ y Néstor Falcón P. ${ }^{3}$
}

\section{Abstract}

A total of 180 serum samples collected in the period of April to September, 2004 from 12 broiler breeder flocks and commercial layers older than 50 weeks of age from ten poultry farms were tested for the presence of Reticuloendotheliosis virus (REV) antibodies using a commercial ELISA test. Only 3 samples were positive to antibodies against REV; however, the optical densities of the 3 positive samples were higher than the negative controls but below to the positive controls. ELISA serologic testing is not definitive and, therefore, it can be concluded that the 12 flocks were negative to REV antibodies. On the other hand, further studies, such as isolation and identification of the virus, are required to achieve a definitive diagnosis.

Key words : reticuloendotheliosis virus, REV, antibodies, ELISA test, breeder hen

La reticuloendoteliosis (RE) aviar describe síndromes complejos que incluyen la neoplasia aguda de células reticulares, la enfermedad del enanismo y las neoplasias crónicas de tejidos linfoides, entre otros (Salem et al., 1989).

El virus de la reticuloendoteliosis (REV) es un retrovirus que no está relacionado con el grupo de virus de la leucosis/sarcoma y presenta un mayor rango de hospederos que otros virus tumorales aviares (Fadly et al., 2004; Witter y Fadly, 2003). El virus se encuentra bastante difundido, pero la enferme- dad clínica no es comúnmente diagnosticada en lotes comerciales de aves. Según la Oficina Internacional de Epizootias (OIE), las enfermedades neoplásicas aviares importantes, desde el punto de vista comercial, son la enfermedad de Marek (herpesvirus), la leucosis aviar y la reticuloendoteliosis aviar (retrovirus). Estas enfermedades son responsables de grandes pérdidas económicas debido a que ocasionan mortalidad y afectan los parámetros productivos (Payne y Venugopal, 2000), constituyendo además una limitación para la exportación de aves.

\footnotetext{
${ }^{1}$ Practica privada. E-mail: salas_elia@hotmail.com

${ }^{2}$ Laboratorio de Patología Aviar, FMV-UNMSM

${ }^{3}$ Laboratorio de Medicina Veterinaria Preventiva, FMV-UNMSM
} 
Cuadro 1. Ubicación de las granjas de gallinas reproductoras y tipo de aves muestreadas para la evaluación de la presencia de anticuerpos contra el virus de la retículo endoteliosis aviar (2004)

\begin{tabular}{|c|c|c|c|c|c|}
\hline \multirow{2}{*}{ Granja $^{1}$} & \multirow{2}{*}{ Lote } & \multirow{2}{*}{ Ubicación } & \multirow{2}{*}{$\begin{array}{c}\text { Edad } \\
\text { (semana) }\end{array}$} & \multicolumn{2}{|c|}{ Ave } \\
\hline & & & & Tipo & Línea \\
\hline 1 & A & Ica & 53 & Carne & Cobb \\
\hline 2 & B & Huaura & 54 & Carne & Cobb \\
\hline 3 & $\mathrm{C}$ & Mala & 69 & Postura & Hy-line \\
\hline 4 & $\mathrm{D}$ & Huarmey & 54 & Carne & Cobb \\
\hline 5 & $\begin{array}{l}\text { E1 } \\
\text { E2 }\end{array}$ & Sayán & $\begin{array}{l}52 \\
56\end{array}$ & Carne & Cobb \\
\hline 6 & $\mathrm{~F}$ & Mala & 52 & Postura & Hy-line \\
\hline 7 & G & Huaura & 62 & Carne & Ross \\
\hline 8 & $\mathrm{H}$ & Huaura & 54 & Carne & Ross \\
\hline 9 & $\begin{array}{l}\text { I1 } \\
\text { I } 2\end{array}$ & Huaura & $\begin{array}{l}74 \\
56\end{array}$ & Postura & Isa Brown \\
\hline 10 & $\mathrm{~J}$ & Canta & 65 & Carne & Ross \\
\hline
\end{tabular}

${ }^{1}$ Se usaron dos lotes de aves en las granjas 5 y 9

El virus es un contaminante potencial de vacunas avícolas. El uso de vacunas contra la difteroviruela aviar y la enfermedad de Marek contaminadas con REV ha sido documentado, y ha tenido considerable consecuencia en la difusión del virus (Medina y Ghazikhanian, 1997; Witter y Fadly, 2003).

Estudios de la evolución y persistencia del virus indican que la frecuencia de parvadas seropositivas se ha incrementando en los últimos 15 años en el norte de EE.UU. (Witter, 1997), reportándose la infección en Israel, EE.UU. Japón y Australia (Jordan, 1990). Las pruebas serológicas de ELISA son aconsejables para determinar el estado de exposición a REV en los lotes de aves (Smith y Witter, 1982). En la actualidad no se tiene conocimiento de reportes ni estudios acerca de la presencia de este agente en el Perú. Debido a esto, se realizó el presente estudio para dar un primer enfoque de la reticuloendoteliosis aviar a través de la de- tección de anticuerpos contra este virus en gallinas mayores de 50 semanas mediante una prueba comercial de ELISA.

Se recolectaron 180 muestras de sangre entre abril y setiembre del 2004 provenientes de 12 lotes de gallinas reproductoras de carne y de postura comercial mayores de 50 semanas de edad. Las aves procedían de 10 granjas localizadas en los departamentos de Lima (9) y de Ica (1). El tamaño de la muestra se obtuvo mediante la fórmula de prevalencia límite. Al no existir estudios previos se eligió la prevalencia de $2 \%$, resultando un número de 149. La identificación y detalles de los lotes examinados se indican en el Cuadro 1.

Se utilizó un kit comercial de ELISA para la detección de anticuerpos contra el virus de la reticuloendoteliosis (Laboratorios IDEXX) en una dilución de 1:500 en solución buffer siguiendo el procedimiento indicado por 
el laboratorio fabricante. Las densidades ópticas fueron medidas a $650 \mathrm{~nm}$ por un lector de ELISA ELX 800 (Biotek Instruments, Inc.).

Las muestras de suero que tuvieron cocientes $\mathrm{M} \not \mathbb{P} \leq 0.05$ se consideraron negativas y aquellas con cocientes $>0.5$ se consideraron positivas.

Dos sueros pertenecientes al lote E2 y un suero del lote $\mathrm{F}$ dieron positivo a la prueba de ELISA, haciendo un total de 3 muestras positivas de las 180 analizadas. Las tres muestras mostraron una baja densidad óptica, pues no llegaron a alcanzar los valores de los controles positivos. Estos resultados sugerirían que hubo exposición a antígenos virales; sin embargo, la interpretación serológica de un lote como positivo a REV ocurre cuando un mínimo de $25 \%$ de las muestras son positivas (R.L. Witter, Comunicación personal). Es necesario señalar además, que durante el periodo que se hizo el estudio, no existieron reportes de problemas o enfermedades tumorales en aves reproductoras, por lo que los resultados serológicos coinciden con los antecedentes clínicos de las aves. También existe la posibilidad de que las aves hayan sido recientemente infectadas y estén en proceso de seroconversión, de allí la baja densidad óptica obtenida en la prueba. Este es el primer estudio realizado sobre este agente en el país, y por ello, un diagnóstico definitivo requiere de pruebas confirmatorias como el aislamiento e identificación del agente por PCR u alguna prueba similar.

La prevalencia de la infección en países como EEUU, Israel y Japón es motivo de preocupación por lo que se debe asegurar la ausencia de anticuerpos contra REV en parvadas de reproductoras, a fin que la progenie pueda ser exportada. Además, se debe comprobar que las neoplasias recientemente diagnosticadas como leucosis linfoide no sean causadas por el REV, ya que ambas enfermedades causan tumores patológicamente idénticos y difíciles de diferenciar. Por último, debería controlarse la posible contaminación de productos biológicos por el REV endémico natural en los EE.UU. (Witter, 1997). Por tanto, sería recomendable realizar monitoreos serológicos para detectar anticuerpos contra el REV en lotes comerciales de reproductoras, que deberían ser incluidos dentro de los programas sanitarios gubernamentales con el fin de garantizar que los lotes comerciales importados sean libres de REV.

\section{Literatura Citada}

1. Fadly, A.M.; R.L. Witter; R. Crespo; I. Davidson; H.M. Hafez. 2004. Retroviruses and Marek's Disease Virus. En: Emerging and remerging diseases. $47^{\text {th }}$ Anual Meeting AAAP/ AVMA. p 33-37. Philadelphia, USA.

2. Jordan, F.T.W. 1990. Reticuloendotheliosis. En: Poultry Diseases. $3^{\text {rd }}$ ed. p 118-120. Ed. Baillere Tindall. University of Liverpool. U.K.

3. Medina, H.A.; Y.G. Ghazikhanian. 1997. Reticuloendotheliosis virus infection in turkeys: Industry Respective. Avian Tumor Viruses Symposium. $40^{\text {th }}$ Annual Meeting AAAP. p 67-69. Reno, USA.

4. Payne, L.N.; K. Venugopal. 2000. Enfermedades neoplásicas: enfermedad de Marek, leucosis aviar y reticuloendoteliosis aviar. Disease of Poultry: World Trade and Public Health Implications. Scientific and Technical Review. Off. Int. Epiz 19(2): 564-544. Disponible en: http://oie.int/esp/publicat/ rt/E_RT19 2htm

5. Salem, M.; J. Eckroade; L.H. Keller. 1989. Experiences using ELISA in a Reticuloendotheliosis outbreak in turkeys. Proc. XXXVIII Western Poultry Disease Conference. p 174-175. Arizona, USA.

6. Smith, E.J.; R.L. Witter. 1982. Detection of antibodies against reticuloendotheliosis viruses by an Enzyme-Linked Immunosorbent Assay. Avian Dis. 27: 225-233. 
7. Witter, R.L. 1997. Avian tumor viruses: persistent and envolving pathogens. Acta Vet. Hung. 45: 251-266.

8. Witter, R.L.; A.M. Fadly. 2003. Reticuloendotheliosis. En: Diseases of poultry. Saif, Y.S.; Barnes, H.J.; Glisson, J.R.; Fadly, A.M.; McDougald, L.R.; Swayne, D.E. (eds). $11^{\text {th }}$ ed. p 517-529. Iowa State University Press. USA. 